\title{
ENL reactions in the multibacillary cases of the AMFES cohort in central Ethiopia: incidence and risk factors
}

\author{
PAUL SAUNDERSON*, SHIBRU GEBRE* \& \\ PETER BYASS** \\ *ALERT, PO Box 165, Addis Ababa, Ethiopia \\ *School of Community Health Science, Nottingham University, \\ Nottingham, UK and Department of Public Health and Clinical \\ Medicine, Umeå University, Umeå, Sweden
}

Accepted for publication 30 June 2000

\begin{abstract}
Summary Erythema nodosum leprosum (ENL), or type 2 leprosy reactions are an important complication of multibacillary leprosy. The AMFES cohort includes 300 new multibacillary cases that have been followed for up to 10 years from the start of treatment, in central Ethiopia. Sixteen (5.3\%) patients had ENL reactions. The incidence of ENL was maximal in the second and third years after the start of treatment, reaching 6.9 episodes per 100 person years at risk. Factors associated with being lepromatous [LL classification and a high bacillary index (BI)] gave an increased risk of developing ENL; in the univariate analysis, LL classification gave a relative risk of $3.6(95 \% \mathrm{CI} 1.3-10)$ and a BI of 6 gave a relative risk of $8.6(95 \% \mathrm{CI}$ 2.3-32) for the development of ENL. HIV co-infection was found to be a risk factor in this cohort, but as the numbers involved are small (only two HIV positive patients had ENL), this finding must be confirmed in larger studies. Ten of the 16 cases had recurrent episodes and five had at least five episodes occurring over a period of more than 2 years. The management and prognosis of ENL reactions are discussed.
\end{abstract}

\section{Introduction}

While erythema nodosum leprosum (ENL) reactions, sometimes known as type 2 reactions, are the most serious immunological complications affecting patients with multibacillary (MB) leprosy, very little has been published on the epidemiology of the condition. ${ }^{1}$ This may be partly because ENL reactions tend to occur some years after the start of multi-drug therapy (MDT) and few studies have involved a long enough follow-up period. Many studies are hospital based and may be expected to find higher rates of reaction than programme-based studies. There is evidence, however, of a wide variation in the frequency of ENL in different parts of the world, with $31 \%$ of MB cases affected in Brazil, ${ }^{2} 19 \%$ in $\mathrm{Nepal}^{3}{ }^{3} 12 \%$ in

Correspondence to: P. Saunderson, ALM, 1 ALM Way, Greenville, SC 29601, USA (e-mail: psaunderson@ leprosy.org) 
Thailand ${ }^{4}$ and $5 \%$ in a previous report from Ethiopia. ${ }^{5}$ The most important risk factor seems to be a high bacillary load, ${ }^{3}$ with LL cases having a higher incidence than BL cases; the condition does not occur in paucibacillary, lepromin positive or smear negative leprosy.

ENL reactions were not reported in HIV-positive individuals until recently and it had been suggested that HIV infection may decrease the risk of this complication. ${ }^{6}$ Case reports of ENL in HIV-positive patients have, however, started to appear. ${ }^{7,8}$

The pathological basis of ENL is considered to be related to circulating immune complexes and the clinical and histological features resemble serum sickness. ${ }^{9}$ In addition to the typical skin lesions, which may rarely ulcerate, a variety of systemic complications have been described, such as orchitis, iridocyclitis, arthritis and nephritis. ${ }^{10}$ Nerve damage may also occur. ${ }^{11}$

\section{Materials and methods}

In all, 660 patients were enrolled in the ALERT MDT Field Evaluation Study (AMFES) between March 1988 and March 1993. Ten patients were excluded, either because the diagnosis was changed or the enrolment procedures were incorrectly followed. A further 56 patients, who were relapses after dapsone monotherapy, are not included in this review. Of 594 new cases 300 were MB cases and form the current study population.

Cases were classified as MB if they were classified clinically as BB, BL or LL in the Ridley-Jopling classification. In addition, BT patients were classified as MB if they had a positive skin smear at any site, although three BT patients with a bacillary index (BI) of 1 were treated as paucibacillary cases in the first year of the study, under earlier guidelines. BT patients with many skin lesions were not classified as MB if their smears were negative. Skin smears were reported for all cases except one MB and 13 PB patients.

Patients were reviewed regularly by field supervisors and the diagnosis of ENL was made on clinical grounds only. Patients were seen on a monthly basis during MDT, and then every 6 months after completion of treatment. Those who did not attend for examination were actively sought, by a home visit if necessary. The diagnosis depended on finding multiple, tender, subcutaneous nodules, usually on the limbs, that were not related to existing leprosy patches. Systemic symptoms could include fever, oedema and other organ involvement. A detailed clinical examination for other organ involvement, including eye complications, was not possible in the peripheral clinics and would only take place for those patients admitted to the ALERT Hospital. If ENL was accompanied by nerve function impairment, steroids were given; otherwise symptomatic treatment with aspirin was given. Prolonged or complicated episodes of ENL were referred to ALERT, where steroids, additional clofazimine and/or thalidomide could be prescribed. The standardized course of steroids for adult MB patients used in peripheral clinics started at a dose of $40 \mathrm{mg}$ prednisolone for $1 \mathrm{month}$, the dose being reduced gradually in monthly steps to finish after 24 weeks. Courses lasting longer than this or involving higher doses of steroids could only be prescribed by physicians to patients attending the ALERT Hospital and these courses varied according to the clinical response, often lasting for more than 12 months.

During the final 2 years of the study all patients with any visual problems who could be traced, were reviewed in the ophthalmology department at ALERT, to document eye pathology, whether leprosy related or not. 


\section{Results}

PREVALENCE AT DIAGNOSIS

There were no cases with ENL at diagnosis.

TIMING OF THE FIRST EPISODE OF ENL

Sixteen $(5.3 \%)$ of $300 \mathrm{MB}$ cases developed ENL at one time or another. Figure 1 shows the timing of the first episode of ENL. Only two of the 16 cases (13\%) presented before the currently advised end of MDT at 1 year. The majority of cases (11 of 16;69\%) first presented in years 2 and 3. There were no new cases of ENL in this cohort more than 6 years after diagnosis.

RISK FACTORS FOR THE DEVELOPMENT OF ENL

Factors linked to being lepromatous are important risk factors for ENL, as shown in Table 1. Sex, pregnancy, nerve function impairment at diagnosis, contact status and delay in presentation were not significant factors. As 25 patients $(8.3 \%)$ did not have an HIV test result available, the multivariate analysis of risk factors was done twice, with and without HIV as a factor. Having a high BI and being HIV positive were important risk factors for ENL in this cohort. HIV status was not associated with BI in either the whole cohort or within the MB group alone.

Because the absolute number of cases with ENL is low and the number of cases in certain sub-groups (for example, HIV positive cases with ENL) is extremely low, Table 1 must be treated with caution. The confidence intervals are wide, reflecting this lack of precision. In this small group, HIV status made no noticeable difference to the clinical features of ENL.

INCIDENCE OF ENL REACTIONS BY YEAR

Figure 2 shows the incidence of ENL reactions by year after the start of treatment. As the disease tends to run a chronic course, it is possibly unhelpful to speak of discrete episodes and therefore of an incidence of reactional episodes. On the other hand, many patients experience remissions and relapses in the course of ENL and two episodes may be separated by a considerable gap. An episode of ENL was taken as a separate event if more than 3 months had

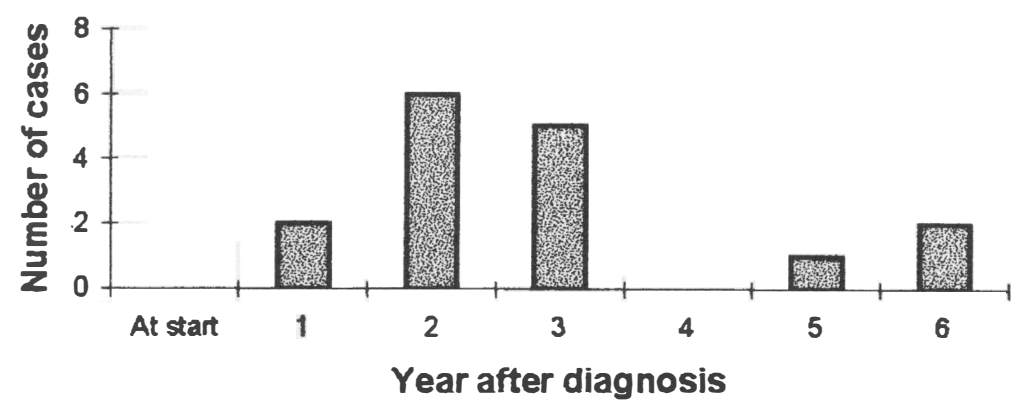

Figure 1. Year of first episode of ENL $(n=16)$. 
Table 1. Risk factors for the development of ENL reactions. NB: one case out of 300 had no BI, while 25 cases had no HIV test done. Two multiple regression models were examined, one including and one excluding HIV as a factor

\begin{tabular}{|c|c|c|c|c|c|}
\hline Factor & Value & $\begin{array}{l}\text { Univariate analysis: } \\
\text { Number of cases } \\
\text { with ENL }\end{array}$ & $\begin{array}{l}\text { Multivariate analysis } \\
\text { relative risk and } \\
(95 \% \mathrm{CI})\end{array}$ & $\begin{array}{l}\text { Multivariate analysis } \\
\text { (no HIV): relative } \\
\text { risk and }(95 \% \mathrm{CI})\end{array}$ & $\begin{array}{l}\text { (with HIV): relative } \\
\text { risk and }(95 \% \mathrm{CI})\end{array}$ \\
\hline \multirow[t]{2}{*}{ Class } & $\mathrm{BT} / \mathrm{BL}$ & $7 / 216$ & $1 \cdot 0$ & & \\
\hline & LL & $9 / 84$ & $3 \cdot 6(1 \cdot 3-10)$ & $1 \cdot 4(0 \cdot 40-5 \cdot 0)$ & $2 \cdot 0(0 \cdot 47-8 \cdot 3)$ \\
\hline \multirow[t]{2}{*}{ Age } & $<20$ & $3 / 76$ & 1.0 & & \\
\hline & $20+$ & $13 / 224$ & $1 \cdot 5(0.42-5 \cdot 4)$ & $1 \cdot 8(0 \cdot 49-6 \cdot 9)$ & $1.4(0.35-5 \cdot 3)$ \\
\hline \multirow[t]{2}{*}{ Sex } & Male & $10 / 205$ & $1 \cdot 0$ & & \\
\hline & Female & $6 / 95$ & $1 \cdot 3(0 \cdot 46-3 \cdot 7)$ & $1 \cdot 8(0 \cdot 60-5 \cdot 5)$ & $1 \cdot 6(0 \cdot 50-5 \cdot 3)$ \\
\hline \multirow[t]{3}{*}{ BI } & $\leq 4$ & $4 / 181$ & $1 \cdot 0$ & & \\
\hline & 5 & $6 / 81$ & $3 \cdot 5(0.97-13)$ & $3 \cdot 3(0 \cdot 77-14)$ & $2 \cdot 8(0 \cdot 55-14)$ \\
\hline & 6 & $6 / 37$ & $8 \cdot 6(2 \cdot 3-32)$ & $8 \cdot 0(1 \cdot 6-42)$ & $5 \cdot 1(0 \cdot 87-31)$ \\
\hline \multirow[t]{2}{*}{ HIV } & Neg & $12 / 265$ & $1 \cdot 0$ & - & \\
\hline & Pos & $2 / 10$ & $5 \cdot 3(1 \cdot 0-2 \cdot 8)$ & - & $7 \cdot 8(1 \cdot 2-52)$ \\
\hline
\end{tabular}

elapsed since the last episode. The figures indicate that episodes of ENL may occur up to 7 years after starting treatment.

\section{CHRONIC AND RECURRENT ENL REACTIONS}

Ten of the 16 cases $(63 \%)$ reviewed here had more than one episode of ENL, which confirms the chronic nature of the condition. The mean and the median number of episodes was three (range 1-8). Amongst these 10 cases, the time between the first and last episodes was on average 22 months (range 4-64 months). Eight of these 10 cases were admitted to hospital at one time or another and another two cases with a single episode were admitted.

Five patients (1.7\% of all MB patients, or $31 \%$ of all ENL cases) had frequent attacks of ENL reaction, with five or more episodes over a period of more than 2 years, but no specific risk factors can be identified, except age, in that all were between 20 and 45 years old. One patient was HIV positive, two were male and none of the females had a pregnancy during the period of observation. The initial BI was 4 in three cases and 5 in two cases. The ages at the start of ENL were 20, 22, 23, 42 and 44 years.

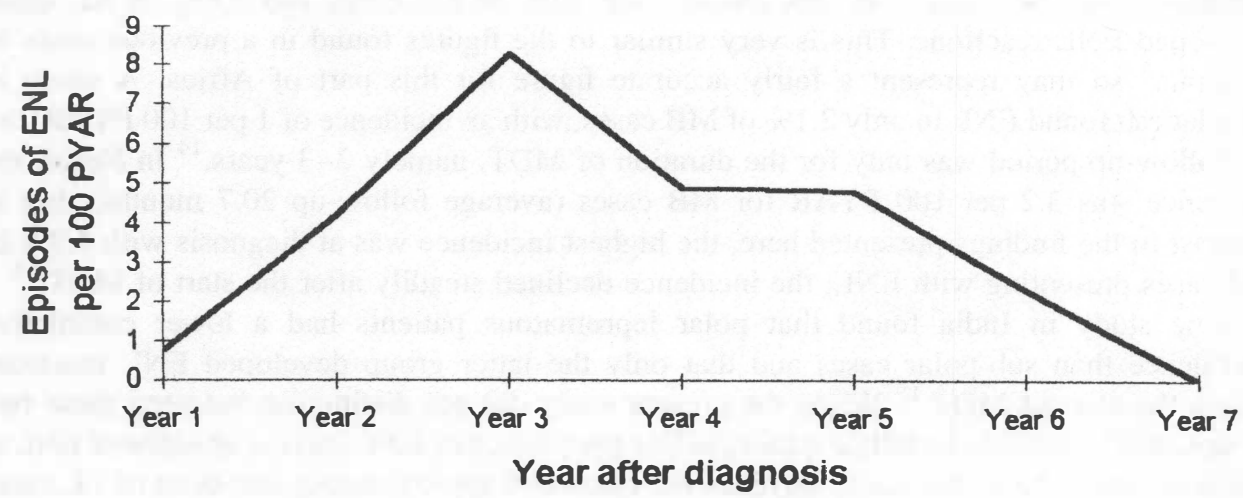

Figure 2. Incidence rate of episodes of ENL, by year after diagnosis (46 episodes in 16 patients). 
MANAGEMENT AND OUTCOME OF CHRONIC ENL REACTIONS

The five cases of chronic ENL were managed with long courses of prednisolone and additional clofazimine, for periods of up to 5 years. The dose of prednisolone was titrated against the clinical features and symptoms of the disease, but a typical maintenance dose was $20 \mathrm{mg}$ daily. Prolonged courses of prednisolone were usually required for symptomatic relief of rheumatic pain and general malaise, rather than for new nerve impairment.

Thalidomide was given to three of these five patients: one female patient (aged 45 at that time) was given it for 3 months as an in-patient when her ENL was at its worst; the short-term results were good in that steroids could be stopped, but there were subsequent episodes of ENL requiring further courses of steroids at varying doses over a period of 64 months in total. Two male patients were each given a short course of thalidomide, early on in the course of the illness. One other patient, without chronic ENL, also had a short course of thalidomide. No patients were treated with thalidomide alone, but received prednisolone as the mainstay of their treatment. Nerve function impairment was always treated with prednisolone, but thalidomide played a useful steroid-sparing role when rheumatic pain and general malaise were the main symptoms.

There was very little deterioration in impairment or disability status over the course of the disease in four patients; the fifth developed sepsis in both feet (at different times) while on steroids, which required debridement, but the eventual outcome has been good. One male patient now requires cataract surgery at the age of 46 years, which may be a complication of steroid treatment.

No systemic involvement was recorded in any of the patients with ENL and no ulceration of nodules occurred. Two patients had conjunctivitis while at ALERT as in-patients, but at the recent ophthalmological review, none of the ENL patients had residual eye pathology, except the cataracts noted above.

\section{Discussion}

ENL reactions have been said to occur in more than $50 \%$ of LL cases and in about $25 \%$ of BL cases, but these figures come from well before the MDT era. ${ }^{12}$ They are known to be frequently prolonged or recurrent, and they are also said to occur more commonly during pregnancy and lactation. ${ }^{13}$ In this cohort only $12 \%$ of LL cases and $3.6 \%$ of BL cases developed ENL reactions. This is very similar to the figures found in a previous study in Ethiopia, ${ }^{5}$ so may represent a fairly accurate figure for this part of Africa. A study in Bangladesh found ENL in only $2.1 \%$ of MB cases, with an incidence of 1 per 100 PYAR, but the follow-up period was only for the duration of MDT, namely 2-3 years. ${ }^{14}$ In Nepal, the incidence was 3.2 per 100 PYAR for MB cases (average follow-up 20.7 months), but in contrast to the findings presented here, the highest incidence was at diagnosis with $5.7 \%$ of MB cases presenting with ENL; the incidence declined steadily after the start of MDT. ${ }^{11}$

One study in India found that polar lepromatous patients had a lower cumulative prevalence than sub-polar cases and that only the latter group developed ENL reactions before the start of MDT. ${ }^{15}$ While the present study did not distinguish between these two groups, this is unlikely to fully explain the low prevalence of ENL and the absence of ENL at diagnosis found here; this study includes BL cases and approximately one-third of LL cases that were biopsied had some histological features suggestive of sub-polar disease. 
The incidence of ENL appears to have fallen with the introduction of MDT, possible explanations being the more rapid bactericidal effect of rifampicin and the specific effect of clofazimine in suppressing ENL. ${ }^{1,16}$ It is clear that as the duration of MDT gets shorter, more ENL reactions will first occur after release from treatment. Patients must therefore be warned of the possibility, so that they may return for further management. While ENL symptoms are severe enough to force the patient to seek treatment, the condition may not be recognized by physicians as it becomes more and more rare. Patients may not volunteer a history of leprosy, so the diagnosis and appropriate treatment may be delayed.

A number of risk factors have been examined, but the low numbers of cases involved make these rather tentative findings. No link with pregnancy or lactation could be confirmed. There is a suggestion that HIV positive cases were more likely to develop ENL reactions. Age under 40 years was a significant risk factor in $\mathrm{Nepal}^{3}$ but in this study age was not a risk factor, although the most chronic cases were all in the age range 20-45 years.

The majority of ENL reactions started in the 2nd or 3rd year after the start of MDT, and most cases had intermittent attacks over a period of about 2 years. Chronic cases were managed with steroids, sometimes over quite long periods, and had a generally good prognosis in terms of nerve damage and disability. Thalidomide use was generally controversial at ALERT Hospital, because of its teratogenic potential, with much discussion before it was prescribed. The drug was not always available, but it was used in $25 \%$ of our cases in short courses. Thalidomide was not given to outpatients in Ethiopia, because of the possibility that it would be shared with others, but it was generally possible to manage chronic ENL with moderate doses of steroids on an outpatient basis, with occasional admissions when necessary.

As approximately one-third of patients with ENL reactions go on to have chronic disease lasting more than 2 years, which requires experience to manage optimally, it is appropriate for most cases to be referred to a physician with such experience, if at all possible. A feasible approach would be to allow one course of treatment in a peripheral clinic (with aspirin or steroids, as indicated), but to advise referral for any subsequent episode of ENL.

\section{Acknowledgements}

We thank the staff of the ALERT Leprosy/TB Control Division for their dedication and perseverance in managing the patients and collecting data over so many years. The financial support of ILEP, through Netherlands Leprosy Relief (NLR), has been constant throughout the 12 years of the study and is gratefully acknowledged. We also thank ALERT as a whole for institutional and administrative support.

\section{References}

${ }^{1}$ Lockwood DNJ. The management of erythema nodosum leprosum: current and future options (Editorial). Lepr Rev, 1996; 67: 253-259.

2 Nery JA, Vieira LMM, de Matos HJ et al. Reactional states in multibacillary Hansen disease patients during multidrug therapy. Rev Inst Med Trop Sao Paulo, 1998; 40: 363-370.

3 Manandhar R, LeMaster JW, Roche PW. Risk factors for erythema nodosum leprosum. Int J Lepr, 1999; 67: $270-278$.

${ }^{4}$ Schreuder PA. The occurrence of reactions and impairments in leprosy: experience in the Leprosy Control Program of three provinces in northeastern Thailand, 1978-1995. II Reactions. Int J Lepr, 1998; 66: 159-169. 
${ }^{5}$ Becx-Bleumink M, Berhe D. Occurrence of reactions, their diagnosis and management in leprosy patients treated with multidrug therapy; experience in the leprosy control program of the All Africa Leprosy and Rehabilitation Training Center (ALERT) in Ethiopia. Int J Lepr, 1992; 60: 173-184.

6 Miller RA. Leprosy and AIDS: a review of the literature and speculations on the impact of CD4+ lymphocyte depletion on immunity to Mycobacterium leprae. Int J Lepr, 1991; 59: 639-644.

7 Olivares LM, Pizzariello GEA, Benetucci J et al. Lepromatous leprosy and HIV infection. Int J Lepr, 1994; 62: 295-296.

8 de Almeida AM, Roselino AMF, Foss NT. Leprosy and HIV infection. Int J Lepr, 1994; 62: 133-135.

9 Hussain R, Lucas SB, Kifayet A et al. Clinical and histological discrepancies in diagnosis of ENL reactions classified by assessment of acute phase proteins SAA and CRP. Int J Lepr, 1995; 63: 222-230.

${ }^{10}$ Ramesh V, Saxena U, Mukherjee A, Misra RS. Multiple ulcers in an elderly man. Necrotizing erythema nodosum leprosum (ENL). Arch Dermatol, 1992; 128: 1643-1646

11 van Brakel WH, Khawas IB, Lucas SB. Reactions in leprosy: an epidemiological study of 386 patients in west Nepal. Lepr Rev, 1994; 65: 190-203.

12 Wemambu SN, Turk JL, Waters MF, Rees RJ. Erythema nodosum leprosum: a clinical manifestation of the Arthus phenomenon. Lancet, 1969; 2: 933-935.

13 Bryceson ADM, Pfaltzgraff RE. Immunological complications: reactions. In: Leprosy, 3rd edn. Churchill Livingstone, Edinburgh, 1990.

${ }^{14}$ Richardus JH, Finlay KM, Croft RP, Smith WC. Nerve function impairment in leprosy at diagnosis and at completion of MDT: a retrospective cohort study of 786 patients in Bangladesh. Lepr Rev, 1996; 67: 297-305.

15 Bhargava P, Kuldeep CM, Mathur NK. Erythema nodosum leprosum in subgroups of lepromatous leprosy. Lepr Rev, 1997; 68: 373-375.

16 Anonymous. Response to treatment by multidrug regimens in the THELEP controlled clinical drug trials. Subcommittee on Clinical Trials of the Chemotherapy of Leprosy (THELEP) Scientific Working Group of the UNDP/World Bank/WHO Special Programme for Research and Training in Tropical Diseases. Lepr Rev, 1996; 67: $260-279$. 